\title{
Detecção de Xylella fastidiosa em Germoplasma de Cafeeiro
}

\author{
Marcos A. Yorinori ${ }^{1 *}$, Alessandra F. Ribas ${ }^{2}$, Bernardo Ueno ${ }^{3}$, Nelson S. Massola Júnior ${ }^{1}$ \\ \& Rui P. Leite Júnior ${ }^{2 * *}$
}

${ }^{1}$ Universidade Estadual de Londrina, CEP 86051-990, Londrina, PR, (43) 3328-4440, e-mail: yorinori@ sercomtel.com.br; ${ }^{2}$ Instituto Agronômico do Paraná, Cx. Postal 481, CEP 86047-902, Londrina, PR, (43) 3376-2289, e-mail: ruileite@ pr.gov.br; ${ }^{3}$ Departamento de Fitopatologia, Universidade de Brasília, CEP 70910-900, Brasília, DF

(Aceito para publicação em 31/03/2003)

Autor para correspondência: Rui Pereira Leite Jr.

YORINORI, M.A., RIBAS, A.F., UENO, B., MASSOLA JÚNIOR, N.S. \& LEITE JÚNIOR, R.P. Detecção de Xylella fastidiosa em germoplasma de cafeeiro. Fitopatologia Brasileira 28:427-430. 2003.

\section{RESUMO}

A bactéria Xylella fastidiosa possui uma ampla gama de plantas hospedeiras que inclui espécies de pelo menos 28 famílias de mono e dicotiledôneas. Em cafeeiro (Coffea spp.), a ocorrência dessa bactéria foi relatada previamente em cultivares da espécie Coffea arabica. Estudos foram realizados para determinar a presença de $X$. fastidiosa em diferentes espécies e híbridos interespecíficos de cafeeiro. As amostragens foram realizadas em dois anos consecutivos. As espécies de cafeeiro examinadas foram: C. kapakata, C. canephora, $C$. racemosa, C. arabica, C. dewevrei, $C$. stenophylla e $C$. eugenioides. Também foram incluídos neste estudo híbridos interespecíficos de $C$. arabica: C. arabica x C. dewevrei, C. arabica x C. eugenioides, $C$. arabica x $C$. racemosa e $C$. arabica $\mathrm{x} C$. robusta. Foram coletadas amostras de ramos plagiotrópicos de diferentes plantas para cada espécie e híbrido. A detecção de X. fastidiosa nas amostras foi realizada utilizando os testes serológicos de DAS-ELISA e imunofluorescência indireta. A bactéria foi detectada nas sete espécies e nos quatro híbridos de cafeeiro examinados. Entretanto, as plantas aparentemente não apresentavam sintomas de infecção por $X$. fastidiosa. A espécie $C$. arabica apresentou a maior proporção de amostras positivas e maiores valores de absorbância no teste de DAS-ELISA. Em contraste, as espécies $C$. racemosa e $C$. dewevrei foram as que apresentaram menores proporções de amostras positivas para presença de $X$. fastidiosa, como também menores valores de absorbância no teste de DAS-ELISA.

Palavras-chave adicionais: café, DAS-ELISA, imunofluorescência indireta, hospedeiro.

\section{ABSTRACT}

\section{Detection of Xylella fastidiosa in coffee germplasm}

The bacterium Xylella fastidiosa has a large host range, including species of 28 different mono and dicotiledoneous plant families. On coffee (Coffea spp.), X. fastidiosa was previously reported only on the species Coffea arabica. Studies were carried out to determine the presence of $X$. fastidiosa in different species and interspecific hybrids of coffee. The species of coffee included in this study were the following: C. kapakata, C. canephora, C. racemosa, C. arabica, C. dewevrei, $C$. stenophylla and C. eugenioides. The interespecific hybrids of $C$. arabica examined were the following: $C$. arabica x $C$. dewevrei, C. arabica $\mathrm{x}$ C. eugenioides, $C$. arabica $\mathrm{x} C$. racemosa and C. arabica $\mathrm{x}$ C. robusta. Samples were collected from plagiotropic branches of different plants for each species or hybrid. Four replicates were examined for each coffee accession examined. Detection of $X$. fastidiosa in the samples was determined by DASELISA and indirect immunofluorescence. The bacterium was detected in all seven species and four hybrids of coffee studied. However, the plants did not show any symptom of infection by $X$. fastidiosa. The species $C$. arabica showed the highest proportion of positive samples and the largest absorbance values in the DASELISA test. In contrast, the species $C$. racemosa and $C$. dewevrei showed the lowest proportion of positive samples for the presence of $X$. fastidiosa, as well as, the lowest absorbance values in the DASELISA test.
A bactéria Xylella fastidiosa Wells et al. (Wells et al., 1987) possui ampla gama de hospedeiros que inclui espécies de pelo menos 28 famílias de plantas mono e dicotiledôneas (Hopkins, 1989; Purcell \& Hopkins, 1996). Apesar de muitas plantas hospedeiras não apresentarem sintomas quando infetadas por X. fastidiosa, elas podem servir como hospedeiros alternativos para a bactéria, constituindo em fontes de inóculo para a ocorrência de doenças em plantas cultivadas (Hopkins, 1989; Leite et al., 1997). Além disso, esta bactéria causa doenças

*Bolsista da CAPES

**Bolsista do CNPq de importância econômica em diversas plantas cultivadas como alfafa (Medicago sativa L.), ameixeira (Prunus salicina Lindl), citros (Citrus spp.), pessegueiro [Prunus persicae (L.) Batsch] e videira (Vitis vinifera L.) (Hopkins, 1989; Purcell \& Hopkins, 1996). A ocorrência de doenças causadas por $X$. fastidiosa já foi reportada nas Américas do Norte, Central e do Sul (Hopkins, 1989; Leite, 2002). Na América do Sul, X. fastidiosa tem sido relatada causando a escaldadura da folha em ameixeira e a clorose variegada em citros na Argentina, Brasil e Paraguai (Leite, 2002). A bactéria também foi constatada causando doença em Catharanthus roseus L. no Estado do Paraná (Ueno et al., 1998). 
O mecanismo de patogenicidade da bactéria sugere que os sintomas produzidos por estresse hídrico sejam causados devido à oclusão de vasos do xilema por agregados da bactéria, gomas e tiloses, podendo também estar associada à presença de fitotoxinas e desbalanço hormonal (Hopkins, 1989; Purcell \& Hopkins, 1996). Além da presença de goma no xilema, também têm sido observadas divisões celulares anormais no xilema, floema e córtex do caule, bem como no mesófilo e no córtex da região da nervura foliar (Queiroz-Voltan et al., 1998).

Xylella fastidiosa é transmitida por material propagativo e por insetos vetores, particularmente cigarrinhas da família Cicadellidae (Hopkins, 1989; Purcell \& Hopkins, 1996). Cigarrinhas presentes na cultura do cafeeiro (Coffea spp.) normalmente pertencem às famílias Cicadidae, Aethalionidae e Cicadellidae (Gallo et al., 1988). Além disso, levantamentos realizados no Estado do Paraná revelaram a presença de mais de 100 diferentes espécies de cigarrinhas em cafeeiros, sendo que pelo menos $80 \%$ dessas espécies pertencem à família Cicadellidae (Lovato et al., 2001).

Xylella fastidiosa foi relatada pela primeira vez ocorrendo em cafeeiro (Coffea arabica L.) da cultivar Mundo Novo no Estado de São Paulo em 1995 (Paradela et al., 1995). Cafeeiros infetados pela bactéria apresentavam ramos com internódios curtos, folhas cloróticas, pequenas e deformadas, abscisão foliar e seca de ramos (Paradela et al., 1995). Sintomas de queima de bordas de folhas também têm sido associados com a infecção de cafeeiro porX. fastidiosa (Lima et al., 1996).

A presença da bactéria associada ao cafeeiro tem sido relatada nas diferentes regiões produtoras de café, dos principais Estados produtores, como São Paulo, Minas Gerais, Paraná, Espírito Santo e Bahia (Paradela et al., 1995; Lima et al., 1996; Ueno \& Leite, 1996). Entretanto, esses relatos têm se restringido às cultivares da espécie $C$. arabica. O presente estudo teve por objetivo investigar a presença de $X$. fastidiosa em diferentes espécies e híbridos interespecíficos de Coffea e determinar a susceptibilidade desse germoplasma à infecção pela bactéria.

Neste estudo foram examinadas plantas de espécies de cafeeiro e híbridos interespecíficos de $C$. arabica com aproximadamente 20 a 23 anos e 13 anos de idade, respectivamente, pertencentes à Coleção de Germoplasma de Cafeeiro do Instituto Agronômico do Paraná - IAPAR. A Coleção está estabelecida em solo do tipo latossolo roxo na Estação Experimental do IAPAR, Londrina, PR, situada na latitude de $23^{\circ} 30^{\prime} \mathrm{S}$, longitude de $51^{\circ} 32^{\prime} \mathrm{W}$ e altitude de $746 \mathrm{~m}$ m.s.l., com as seguintes médias climáticas anuais: temperatura $20,3{ }^{\circ} \mathrm{C}$, umidade relativa $69 \%$ e precipitação $1.727,5 \mathrm{~mm}$. Foram examinadas sete espécies de cafeeiro: $C$. arabica, C. canephora Pierre, C. dewevrei de Wild y Durand, C. eugenioides Moore, C. kapakata (A. Chev.) Bridson, C. racemosa Lour. e C. stenophylla $\mathrm{G}$. Don e quatro híbridos, C. arabica $\mathrm{x}$ C. dewevrei, C. arabica x C. eugenioides, C. arabica x C. racemosa e $C$. arabica $\mathrm{x} C$. robusta. As avaliações foram realizadas em dois anos consecutivos. Foram coletadas quatro amostras de ramos plagiotrópicos com aproximadamente 0,4 a $0,6 \mathrm{~cm}$ de diâmetro de plantas diferentes para cada espécie e híbrido, com quatro repetições, sendo que cada repetição foi constituída de uma planta diferente.

Para detecção de $X$. fastidiosa nas diferentes espécies e híbridos interespecíficos de cafeeiro foram utilizados os testes serológicos de ELISA ("enzyme-linked immunosorbent assay") e imunofluorescência indireta. O procedimento do teste de ELISA empregado foi o DAS-ELISA ("Double Antibody Sandwich") (Clark et al., 1986). O teste de DAS-ELISA foi realizado basicamente conforme descrito por Leite et al. (1997). As amostras foram consideradas positivas ou suspeitas para a presença de $X$. fastidiosa quando a média dos valores de absorbância a $410 \mathrm{~nm}$ foi pelo menos três vezes maior do que os valores médios obtidos para o controle tampão de extração (Clark \& Adams, 1977).

Para o teste de imunofluorescência indireta foi utilizado o protocolo descrito por De Boer (1990) com algumas modificações. Foram adicionados $30 \mu \mathrm{l}$ de água destilada em cada vaso das lâminas de imunofluorescência e a seguir os ramos foram cortados em segmentos pequenos e espremidos com alicate sobre a gota de água no vaso. A seiva do ramo foi misturada de forma que a amostra ficasse homogênea. As amostras foram fixadas nas lâminas por secagem, utilizando secador de cabelos. A seguir, as amostras foram tratadas com etanol $96 \%$ por $10 \mathrm{~min}$. O anticorpo específico para $X$. fastidiosa (Leite et al., 1997) foi diluído a 1:500 em PBS + 0,2\% de leite desnatado (agente bloqueador). Foram adicionados $20 \mu \mathrm{l}$ do anticorpo primário diluído em cada vaso da lâmina e estas foram incubadas em câmara úmida a $37^{\circ} \mathrm{C}$ por $30 \mathrm{~min}$. As lâminas foram lavadas com água destilada por três vezes e deixadas em PBS por 30 min para retirar o excesso de anticorpo primário. As lâminas foram novamente secas com secador de cabelos. Em seguida, $20 \mu \mathrm{l}$ do anticorpo secundário diluído (1:200 anticorpo específico para imunoglobulina de coelho conjugado com corante fluorescente TRITC; isotiocianato de tetrametilrodamina em PBS) $+0,2 \%$ de leite desnatado foi colocado em cada vaso da lâmina. As amostras foram então incubadas em condição de escuro em câmara úmida por $30 \mathrm{~min}$. As lâminas foram lavadas com água destilada por três vezes e colocadas em PBS por 30 min para retirar o excesso de anticorpo secundário. As lâminas passaram novamente por processo de secagem e em seguida, foram montadas com uma gota de solução $90 \%$ de glicerol + 10\% PBS sobre cada vaso da lâmina. As lâminas foram observadas em microscópio com lâmpada fluorescente em aumento de 400 vezes. As amostras foram consideradas positivas quando foi possível observar células bacterianas fluorescentes.

As avaliações para determinar a presença da bactéria $X$. fastidiosa em diferentes espécies e híbridos interespecíficos de cafeeiro foram realizadas em dois anos consecutivos, 1998 e 1999 (Tabela 1). No primeiro ano de avaliação, apenas as espécies $C$. racemosa e $C$. dewevrei não apresentaram resultados positivos para presença de X. fastidiosa, em nenhuma das duas técnicas utilizadas (Tabela 1). No segundo ano, todas as espécies e híbridos examinados apresentaram resultados positivos para presença da bactéria pelo teste de DAS-ELISA (Tabela 1). A espécie $C$. arabica foi a que 
apresentou os valores mais elevados de absorbância no teste de DAS-ELISA entre as sete espécies de Coffea examinadas (Tabela 1). Além disso, todas as amostras de $C$. arabica examinadas apresentaram resultados positivos para presença de $X$. fastidiosa (Tabela 1). Em contraste, as demais espécies não apresentaram resultados positivos para todas as amostras (Tabela 1). As espécies $C$. racemosa e $C$. dewevrei foram as que apresentaram menores proporções de amostras positivas, como também menores valores de absorbância no teste de DAS-ELISA no ano de 1999, da mesma forma que $C$. stenophylla em 1998 (Tabela 1).

Entre os híbridos interespecíficos, os genótipos $C$. arabica x $C$. eugenioides e $C$. arabica x $C$. robusta apresentaram os valores mais elevados de absorbância no teste de DAS-ELISA para presença de $X$. fastidiosa, como também as maiores proporções de amostras positivas nos testes de DASELISA e imunofluorescência para presença da bactéria (Tabela 1). Por outro lado, o híbrido interespecífico $C$. arabica $\mathrm{x} C$. dewevrei apresentou os menores valores para incidência da bactéria e absorbância no teste de DAS-ELISA realizados em 1998 (Tabela 1)

As diferenças observadas entre as amostras de um mesmo genótipo nos testes serológicos de DAS-ELISA e imunofluorescência para presença de $X$. fastidiosa podem ser atribuídas a diversos fatores, como, por exemplo, à distribuição não uniforme da bactéria nos tecidos da planta (Hopkins, 1989; Purcell \& Hopkins, 1996). A bactéria X. fastidiosa não apresenta colonização uniforme dos vasos do xilema da planta hospedeira, sendo encontrada normalmente na forma de agregados, que tendem a se acumular em partes específicas da planta (Purcell \& Hokpins, 1996). Outro fator a ser considerado está relacionado à amostragem de tecido vegetal para o teste de
DAS-ELISA, no qual normalmente é utilizado somente 1,5 g de tecido, possibilitando desta forma a ocorrência de variações nos resultados de detecção da bactéria. Em último caso, podese considerar que as plantas poderiam realmente não estar infetadas pela bactéria $X$. fastidiosa.

Cabe ressaltar que o teste de imunofluorescência indireta revelou maior sensibilidade na detecção de $X$. fastidiosa do que o teste de DAS-ELISA. Isto pode ser exemplificado pelos resultados obtidos no primeiro ano de avaliação do germoplasma de cafeeiro, quando foram utilizadas as duas técnicas para detecção da bactéria. Nesta avaliação, a presença de $X$. fastidiosa não foi detectada somente nas espécies $C$. dewevrei e $C$. racemosa pelo teste de imunofluorescência, enquanto que pelo teste de DAS-ELISA, a bactéria não foi detectada em quatro acessos de cafeeiro (Tabela 1). Este resultado não é surpreendente visto que o teste de imunofluorescência está entre as técnicas mais sensíveis para detecção de bactérias, com nível de sensibilidade de até 1.000 vezes superior ao teste de DAS-ELISA (Saettler $e t$ al., 1989).

De modo geral, os resultados obtidos indicam que as diferentes espécies e híbridos de Coffea são hospedeiros de $X$. fastidiosa. Estes resultados vêm ampliar a gama de plantas hospedeiras de $X$. fastidiosa, que já incluem centenas de espécies de plantas mono e dicotiledônias distribuídas em pelo menos 28 famílias (Hopkins, 1989; Purcell \& Hopkins, 1996). Entretanto, as plantas de espécies e híbridos de cafeeiro examinadas não apresentavam sintomas de alterações no desenvolvimento em função de infecção por X. fastidiosa. Os sintomas normalmente associados à infecção por $X$. fastidiosa variam com a planta hospedeira e são os mais diversos possíveis. Entre os sintomas mais comuns de doenças

TABELA 1 - Reação de espécies e híbridos interespecíficos de cafeeiro (Coffea spp.) aos testes de DAS-ELISA e imunofluorescência indireta para presença de Xylella fastidiosa

\begin{tabular}{|c|c|c|c|c|c|}
\hline \multirow{3}{*}{ Germoplasma de Cafeeiro } & \multicolumn{3}{|c|}{ Incidência } & \multirow{2}{*}{\multicolumn{2}{|c|}{$\begin{array}{c}\text { Valor Médio de AbsorBância } \\
\text { DAS-ELISA }^{\text {c }} \\
\end{array}$}} \\
\hline & \multicolumn{2}{|c|}{ DAS-ELISA $^{\text {a }}$} & \multirow{2}{*}{$\begin{array}{c}\text { Imuno }^{b} \\
1998\end{array}$} & & \\
\hline & 1998 & 1999 & & 1998 & 1999 \\
\hline Espécic & & & & & \\
\hline C. canephora & $2 / 2$ & $3 / 4$ & $3 / 4$ & $0,068(+)$ & $0,081(+)$ \\
\hline C. racemosa & $0 / 2$ & $2 / 4$ & $0 / 2$ & $0,023($ & $0,078(+)$ \\
\hline C. arabica & $2 / 2$ & $4 / 4$ & $2 / 2$ & $0,050(+)$ & $0,209(+)$ \\
\hline C. dewevrei & $0 / 2$ & $3 / 4$ & $0 / 2$ & $0,011($ & $0,055(+)$ \\
\hline C. stenophylla & $0 / 2$ & $2 / 4$ & $2 / 2$ & $0,021($ & $0,136(+)$ \\
\hline C. eugenioides & $2 / 2$ & $3 / 4$ & $2 / 4$ & $0,040(+)$ & $0,158(+)$ \\
\hline Híbrido Interespecífico & & & & & \\
\hline C. arabica $\mathrm{x} C$. dewevrei & $0 / 2$ & $2 / 4$ & $1 / 2$ & $0,002($ & $0,107(+)$ \\
\hline C. arabica $\times$ C. engenioides & $2 / 2$ & $3 / 4$ & $2 / 2$ & $0,058(+)$ & $0,224(+)$ \\
\hline C. arabica $\mathrm{x}$ C. racemosa & $1 / 2$ & $3 / 4$ & $1 / 2$ & $0,040(+)$ & $0,040(+)$ \\
\hline C. arabica $\times$ C. robusta & $1 / 2$ & $2 / 4$ & $2 / 2$ & $0,050(+)$ & $0,307(+)$ \\
\hline Isol. de $X . f .10^{6} \mathrm{ufc} / \mathrm{ml}^{\mathrm{d}}$ & & & & 0,307 & 0,212 \\
\hline Tampão de extração & & & & 0,013 & 0,009 \\
\hline
\end{tabular}

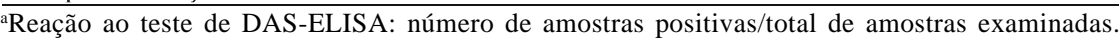

bReação ao teste de imunofluorescência indireta: número de amostras positivas/total de amostras examinadas.

${ }^{c}(+)$, reação positiva e $(-)$, reação negativa. As amostras foram consideradas positivas quando a média dos valores de absorbância a 410 nm obtidos

em leitora de ELISA foi pelo menos 3 vezes maior que o valor médio do tampão de extração.

${ }^{d}$ Suspensão bacteriana de $X$. fastidiosa preparada em tampão de extração. 
causadas por $X$. fastidiosa estão as queimas de bordos de folhas, secas de ramos, encurtamentos de internódios, reduções de crescimento e declínios generalizados (Hopkins, 1989; Purcell \& Hopkins, 1996). A ocorrência de hospedeiros assintomáticos para $X$. fastidiosa tem sido relatada na literatura por vários autores (Hopkins, 1989; Purcell \& Hopkins, 1996). Além disso, a manifestação de sintomas de doenças causadas por $X$. fastidiosa normalmente pode demorar meses ou até anos (Hopkins, 1989; Purcell \& Hopkins, 1996). De qualquer forma, plantas infetadas por $X$. fastidiosa, mesmo sem apresentar qualquer sintoma, são fontes potenciais de inóculo da bactéria (Colleta Filho et al., 1998). Os resultados obtidos no presente estudo ampliam a gama de plantas hospedeiras de $X$. fastidiosa, incluindo diferentes espécies de Coffea e híbridos interespecíficos de C. arabica.

\section{AGRADECIMENTOS}

Nossos agradecimentos ao CNPq e Consórcio Brasileiro de Pesquisas e Desenvolvimento do Café - CBPD/Café pelo apoio financeiro. Tumoro Sera, José Alves e Caio K. Funada deram suporte técnico para a realização dos trabalhos.

\section{REFERÊNCIAS BIBLIOGRÁFICAS}

CLARK, M.F. \& ADAMS, A.N. Characteristics of the microplate method of enzyme-linked immunosorbent assay for the detection of plant viruses. Journal of General Virology 34:475-483. 1977.

CLARK, M.F., LISTER, R.M. \& BAR-JOSEPH, M. ELISA techniques. Methods in Enzymology 118:742-766. 1986.

COLLETA FILHO, H.D., BORGES, K.M. \& MACHADO, M.A. Detecção de Xylella fastidiosa em plantas matrizes de laranja doce assintomáticas para a CVC. Fitopatologia Brasileira 23:208. 1998 (Resumo).

DE BOER, S.H. Immunofluorescence for bacteria. In: Hampton, R.O., Ball, E.M. \& De Boer, S.H. (Eds.) Serological Methods for Detection and Identification of Viral and Bacterial Plant Pathogens. St. Paul, MN. APS Press. 1990. pp.295-298.

GALLO, D., NAKANO, O., SILVEIRA NETO, S., CARVALHO, R.P.L., BATISTA, G.C., BERTI FILHO, E., PARRA, J.R.P., ZUCCHI, R.A., ALVES, S.B. \& VENDRAMIM, J.D. Manual de Entomologia Agrícola. 2ª ed. São Paulo. Ceres. 1988.
HOPKINS, D.L. Xylella fastidiosa: Xylem-limited bacterial pathogen of plants. Annual Review of Phytophatology 27:271-290. 1989.

LEITE, JR., R.P. Ocorrência de Xylella em café no Brasil. Programa e Resumos XXV Congresso Paulista de Fitopatologia. Espírito Santo do Pinhal, SP. 2002. pp.32-34.

LEITE, R.M.V.B.C., LEITE, JR., R.P. \& CEREZINE, P.C. Flutuação populacional de Xylella fastidiosa em ameixeiras suscetíveis e resistentes à escaldadura da folha. Fitopatologia Brasileira 22:58-63. 1997.

LIMA, J.E.O. de, MIRANDA, V.S., COUTINHO, A., ROBERTO, S.R. \& CARLOS, E.F. Distribuição de Xylella fastidiosa no cafeeiro nas regiões cafeeiras, e seu isolamento in vitro. Fitopatologia Brasileira 21:392-393. 1996.

LOVATO, L., SIMÕES, H.C., ZANDONÁ, C., MENEGUIM, A.M. \& LEITE, JR., R.P. Ocorrência de cigarrinhas vetoras da bactéria Xylella fastidiosa em lavouras cafeeiras no estado do Paraná. Resumos Expandidos do II Simpósio de Pesquisas dos Cafés do Brasil, Vitória, ES, Brasil. 2001.

PARADELA FILHO, O., SUGIMORI, M.H., RIBEIRO, I.J.A., MACHADO, M.A., LARANJEIRA, F.F., GARCIA JR., A. \& BERETA, M.J.G. Primeira constatação em cafeeiro no Brasil da Xylella fastidiosa causadora da clorose variegada dos citros. Laranja 16:135136. 1995.

PURCELL, A. \& HOPKINS, D.L. Fastidious xylem-limited bacterial plant pathogens. Annual Review of Phytopathology 34:131-151. 1996.

QUEIROZ-VOLTAN, R.B., PARADELA FILHO, O., CARELLI, M.L.C. \& FAHL, J.I. Aspectos estruturais de cafeeiro infectado com Xylella fastidiosa. Bragantia 57:23-33. 1998.

SAETTLER, A.W., SCHAAD, N.W. \& ROTH, D.A. Detection of Bacteria in Seed and Other Planting Material. St. Paul, MN. APS Press. 1989.

UENO, B. \& LEITE, JR., R.P. Estudo da variabilidade de isolados de Xylella fastidiosa obtidos de cafeeiro e citros através da análise de proteínas totais. Fitopatologia Brasileira 21:341. 1996 (Resumo).

UENO, B., FUNADA, C.K., YORINORI, M.A. \& LEITE, JR., R.P. First report of Xylella fastidiosa on Catharanthus roseus in Brazil. Plant Disease 82:720-720. 1998.

WELLS, J.M., RAJU, B.C., HUNG, H.Y., WEISBURG, W.G., MANDELCO-PAUL, L. \& BRENNER, D.J. Xylella fastidiosa gen. nov. sp. nov.: Gram-negative, xylem-limited fastidious plant bacteria related to Xanthomonas spp. International Journal of Systematic Bacteriology 37:136-143. 1987. 